eine mindestens doppelt so reichhaltige Brucinlösung genommen werden, aus welcher über Nacht die Krystalle anschiessen.

\title{
Das Verhalten von Meerwasser zu Blel.
}

Von Dr. Kaiser, Assistent an der Versuchsstation zu Jena.

Es ist in neuester Zeit vorgeschlagen worden, die bei Seewasser-Aquarien bisher gebräuchlichen Glasröhren durch solche von Blei zu ersetzen. Abgesehen nun davon, dass bei dieser Anwendungsart Glasröhren manche Vorzüge vor Błeiröhren besitzen, war es bei der grossen Empfindlichkeit vieler Seethiere gegen anomale Einflüsse wichtig, festzustellen, dass das zu den Röhren verwendete Blei von dem Meerwasser nicht in der Art angegriffen wird, dass eine in letzterem lösliche Verbindung desselben entsteht. - Durch die gütige Vermittlung des Herrn Dr. v. Koch hier erhielt ich für diese Untersuchung Meerwasser aus dem Golf von Neapel. In eine damit zu zwei Dritteln gefullte, ein Liter haltende, Flasche wurden ungefähr dreissig Gramm frisch geschnittene Bleischnitzel gethan und dieselben mit dem Wasser täglich häufig geschüttelt. Nach vier Tagen wurde filtrirt, und das Filtrat auf eine gelöste Bleiverbindung untersucht. Es konnte jedoch keine nachweisbare Spur einer solchen aufgefunden werden. Die ursprünglich glänzenden Schnittflächen der Bleischnitzel hatten sich jedoch mit einer aus einer unlöslichen Bleiverbindung bestehenden Schicht überzogen, welche durch Behandlung mit weinsaurem Ammoniak in Lösung ging und die bekannten Bleireactionen gab. Wie sich hieraus ergiebt, steht der Verwendung, von Bleiröhren zu dem eben erwähnten Zwecke Nichts im Wege, jedoch dürften auch hier, wenn man Glasröhren vermeiden will, die für Wasserleitungszwecke mehr und mehr in Aufnahme kommenden Bleiröhren mit innerer Verzinnung den Vorzug verdienen. 